\title{
PRODUÇÃO MAIS LIMPA: UMA FERRAMENTA DE GESTÃO AMBIENTAL APLICADA EM UM PROCESSO DE FABRICAÇÃO DE LAJES.
}

\author{
Arthur Pereira dos Santos, Elson Mendonça Felici. \\ Universidade do Oeste Paulista - Unoeste, Engenharia Ambiental e Sanitária, Presidente Prudente, SP. E-mail: \\ arthurpdosantos@outlook.com.
}

\begin{abstract}
RESUMO
O aumento da competitividade do mercado ocasionou na maior exigência dos consumidores, que visam uma melhor qualidade do produto vinculado à responsabilidade ambiental das empresas. Nesse sentido, o objetivo deste estudo foi propor estratégias para melhoria do processo produtivo com base nos princípios de Produção Mais Limpa, visando a minimização dos impactos ambientais gerados em uma empresa de fabricação de lajes. Utilizou-se o método qualitativo para análise das informações coletadas, observando diretamente o comportamento no processo das atividades e dos resíduos e impactos ambientais gerados. Realizou-se um diagnóstico que auxiliou na elaboração de propostas de melhoria em diversas áreas e processos da empresa. As propostas visaram otimizar o processo produtivo, preservando o meio ambiente e recursos naturais. Ao final do processo, concluiu-se que existe a ampla necessidade de uma gestão ambiental eficaz e efetiva na empresa estudada, considerando que ela ainda apresenta um déficit relacionado à preocupação ambiental.
\end{abstract}

Palavras-chave: Produção mais limpa, Gestão ambiental, Melhoria contínua, Resíduos, Impacto ambiental.

\section{CLEANER PRODUCTION: AN ENVIRONMENTAL MANAGEMENT TOOL APPLIED IN A LAJES MANUFACTURING PROCESS.}

\begin{abstract}
The increase in the competitiveness of the market has led to greater requirements from consumers, which aim a better product quality linked to the environmental responsibility of companies. In this sense, the objective of this study was to propose strategies to improve the production process based on the principles of cleaner production, aiming to minimizing the environmental impacts generated in a slab manufacturing company. The qualitative method was used to analyze the information collected, directly observing the behavior of the activities and of the residues in the process and the impacts generated. A diagnosis that helped in the elaboration of proposals for improvement in several areas and processes of the company was made. The proposals aimed to optimizing the production process, preserving the environment and natural resources. At the end of the process, it was concluded that there is a great need for an efficient and effective environmental management in the company studied, considering that it is still a deficit related to environmental concern.

Keywords: Cleaner production, Environmental management, Contínuos improvement, Combings, Environmental impact.
\end{abstract}




\section{INTRODUÇÃO}

Atualmente, devido à competitividade entre os mercados, existe uma maior exigência dos consumidores que, além de procurar por um produto de melhor qualidade, visam também fatores como a responsabilidade ambiental e social da empresa. Diante do exposto, ocorrem inúmeros impactos ambientais ocasionados pelo grande número de resíduos industriais gerados, fato este que está sendo frequentemente observado e monitorado no cenário mundial.

O impacto ambiental se caracteriza por toda e qualquer mudança provinda de forma negativa no meio ambiente, tendo por origem a influência humana. No que se refere à produção de lajes, os principais impactos ambientais envolvidos são: ar, solo e água. Sua origem tem início desde antes do processo de fabricação, levando em consideração que o cimento gera cerca de $5 \%$ das emissões de CO2 no mundo. (eCycle, 2013).

Por este cenário permanecer atualmente no mercado, existem ferramentas que possibilitam a obtenção de resultados positivos dentro da empresa. Dentre elas, destaca-se a Produção Mais Limpa, que segundo a UNEP (Programa das Nações Unidas para o Meio Ambiente), consiste na aplicação contínua de uma estratégia econômica, ambiental e tecnológica integrada aos processos e produtos, que evita a geração, minimiza ou recicla os resíduos gerados pelos processos produtivos, com a finalidade de aumentar a eficiência na utilização das matérias-primas, água e energia e de reduzir os riscos para as pessoas e para o meio ambiente.

Diante do exposto, realizou-se o presente trabalho que teve como objetivo geral propor estratégias para melhoria do processo produtivo de uma organização, com base nos princípios de Produção Mais Limpa, visando à minimização dos impactos ambientais gerados na empresa e aumento da sua vantagem econômica e competitiva, adequando a empresa de acordo com as exigências do mercado. Para tanto, como objetivos específicos, buscou-se entender e mapear o processo produtivo da empresa; analisar a geração de resíduos e os impactos ambientais gerados no processo produtivo e no meio ambiente; e elaborar propostas para aplicar as ferramentas da Produção Mais Limpa, com o intuito de minimizar a geração de resíduos e a geração de impactos ambientais da fabricação de lajes.

A empresa em questão está localizada no oeste paulista, produz lajes pré-moldadas, mourões de concreto curvo e reto, pé direito de área, vigas de concreto, blocos de concreto, tampas de caixa de inspeção e equipamentos para construção civil. A coleta de resíduos é feita conforme a necessidade e demanda (em média, uma vez por semana) e se dá através de caçambas por uma empresa especializada, sendo que a mesma faz o descarte do material coletado. Para o tratamento de esgoto, é utilizada fossa séptica para destinação dos efluentes domésticos, e a água consumida é proveniente da rede de abastecimento da cidade.

\section{METODOLOGIA}

Realizou-se a pesquisa no próprio local de fabricação de lajes, onde os pesquisadores entraram em contato com todo o processo, desde o início até o fim da produção. Contou-se com a ajuda do proprietário da fábrica, que apresentou o processo etapa por etapa, tirando dúvidas sobre etapas do processo e respondendo questões de forma clara e objetiva.

A estruturação da metodologia foi descrita visando três passos. Inicialmente, realizou-se um diagnóstico da empresa para conhecer e entender de forma aprofundada cada etapa e processos a serem realizados na fabricação das lajes, da entrada da matéria-prima à obtenção de seu produto final.

Em seguida, observaram e verificaram, de forma precisa, os métodos utilizados na produção, onde cada matéria-prima é utilizada, e, caso descartado, qual o motivo e onde é feito este descarte. Observaram o local de estoque de produtos e suas respectivas quantidades; layout da empresa; forma que os colaboradores trabalham para fabricar as lajes; como são feitos os pedidos e; de que forma são entregues. Todos os locais onde são estocadas as matérias primas 
(cimento, pedra, areia, lajotas e lajes prontas para utilização) foram visitados. Verificou-se também a existência de algum tipo de resíduo proveniente de cortes das lajes que poderia ser vendido como produto secundário, aumentando assim, o capital da empresa e consequentemente diminuindo entulhos.

Todavia, procurou-se analisar possíveis alternativas, que suportem o processo e minimizem desperdícios, não só de matéria-prima, mas também de tempo e esforço dos colaboradores. Através desta análise, foi possível identificar e avaliar os impactos ambientais causados pelo descarte em locais incorretos de entulhos, e com isso procederam a propostas de melhoria para estes problemas.

As propostas são desenvolvidas e entregues ao dono da empresa, cabendo a ele a decisão de implanta-las. Evidenciam que não há necessidade de todas serem executadas para suceder uma melhoria no processo. Seguindo as etapas de acordo com os passos aplicados, realizou-se um melhor desenvolvimento da pesquisa e uma melhor visão de horizonte para os pesquisadores, facilitando sua compreensão e execução da ferramenta de gerenciamento.

\section{RESULTADOS}

Para melhor entendimento do processo, desenvolveu-se um fluxograma detalhado da fabricação das lajes, indicando todas as etapas do processo produtivo, conforme pode ser observado na Figura 1.

Figura 1: fluxograma do processo.

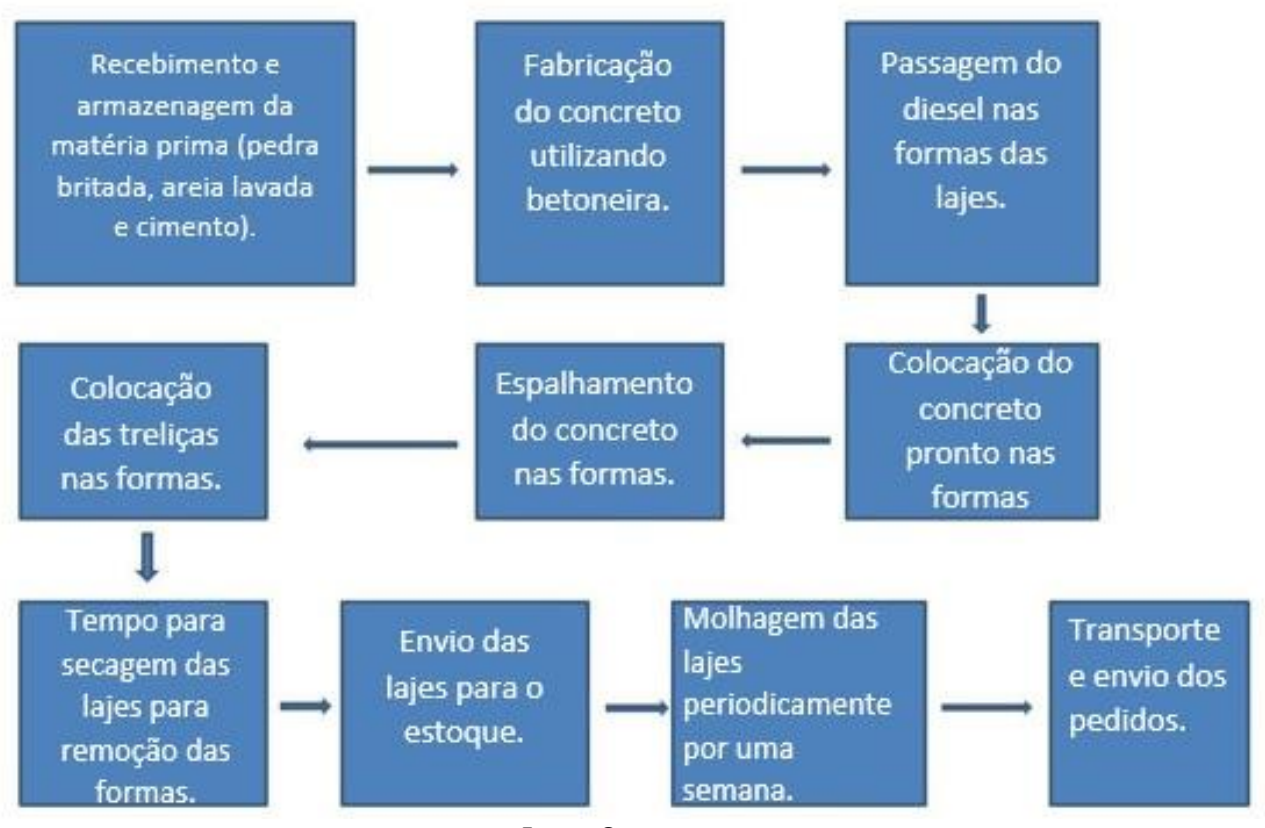

Para desenvolvimento de resultados e sugestões de melhoria na empresa, os pesquisadores analisaram as formas em que a PML atua dentro de um processo de produção, conforme pode ser observado na Figura 2. 
Figura 2: formas de atuação da PML em um processo.

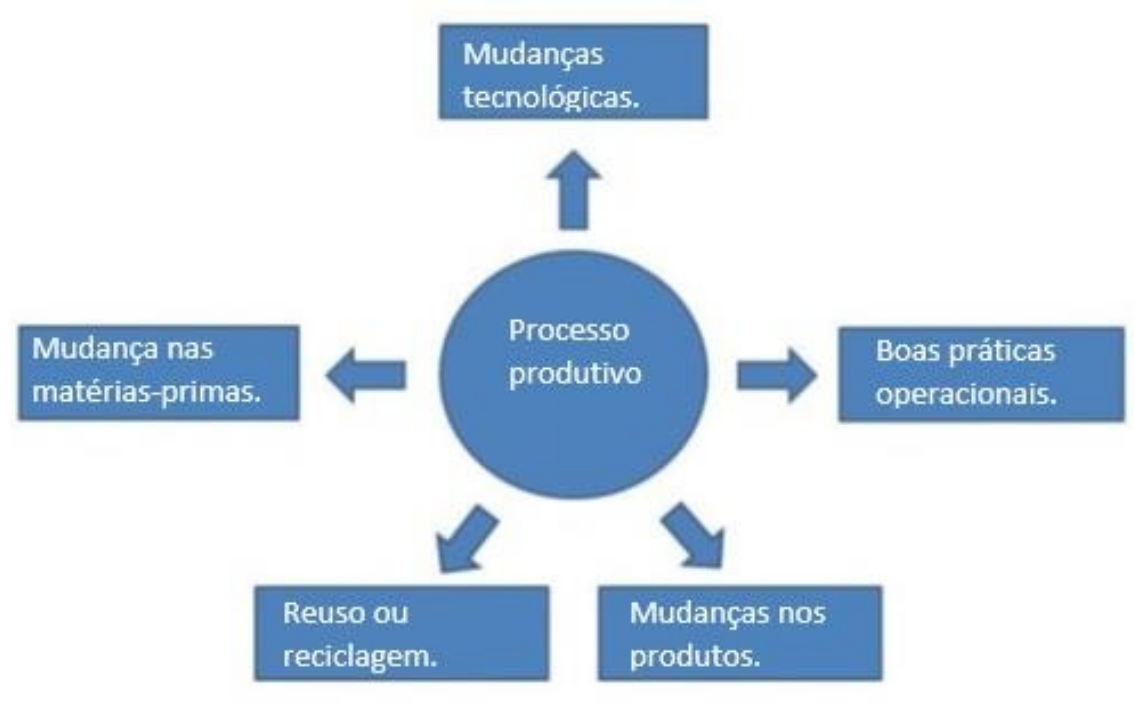

Fonte: Os autores.

No processo de fabricação das lajes, são gerados dois grandes tipos de impactos que influenciam no meio ambiente e na sociedade: quantidade de entulho que é gerado pelo processo e o gasto excessivo de água.

Em relação aos resíduos, observou-se a geração de resíduos recicláveis no escritório (papel, papelão, plástico e copos descartáveis), além dos resíduos gerados no processo produtivo (sacos de cimento e resíduos da construção civil), que são descartados pela empresa terceirizada.

Durante a realização da pesquisa, os únicos resíduos perigosos gerados foram algumas pilhas dos controles de equipamentos de ar condicionado e eventuais peças de computadores que necessitaram de troca.

O Quadro 1 apresenta a classificação dos resíduos gerados pela empresa, de acordo com a NBR 10.004/2004 e Conama № 307/2002.

Quadro 1: resíduos gerados na empresa.

\begin{tabular}{|l|c|c|c|}
\hline \multirow{2}{*}{ Resíduo Gerado } & \multicolumn{2}{|c|}{ Classes } & \multirow{2}{*}{ Características } \\
\cline { 2 - 3 } & $\begin{array}{c}\text { Conama No } \\
\mathbf{3 0 7 / 0 2}\end{array}$ & $\begin{array}{c}\text { ABNT/NBR } \\
\mathbf{1 0 . 0 0 4 / 0 4}\end{array}$ & Não perigoso \\
\hline Sacos de cimento & B & II & Não perigoso \\
\hline $\begin{array}{l}\text { Restos de concreto e } \\
\text { lajes }\end{array}$ & A & II & Não perigoso \\
\hline Aço & A & II & Não perigoso \\
\hline $\begin{array}{l}\text { Resíduos recicláveis } \\
\text { escritório }\end{array}$ & B & II & Não perigoso \\
\hline Rejeitos (banheiro) & B & II & Perigoso \\
\hline Resíduos Eletrônicos & C & I & I \\
\hline
\end{tabular}

Fonte: ABNT/NBR 10.004/04; CONAMA № 307, de 5 de julho de 2002.

Verificou-se que a empresa não possui um Plano de Gerenciamento de Resíduos Sólidos (PGRS) implantado. Os restos de ferro proveniente de pedaços de treliças que foram cortadas podem vir a causar outro tipo de problema no local do descarte: a ferrugem que se dará pelo seu 
contato com o oxigênio no ar ou na água, gerando oxidação, e, conforme a chuva, a ferrugem é espalhada no solo, podendo ser responsável pela contaminação deste, atingindo consequentemente os lençóis freáticos. $O$ ideal é que estes resíduos sejam descartados em locais adequados.

Quanto ao uso de água, as lajes precisam ser molhadas periodicamente após irem para o estoque, com o objetivo de curar o concreto e deixa-lo mais resistente. Isto é feito no período de no mínimo uma semana e ao menos três vezes ao dia. Pelo fato da água não ser reaproveitada, todos os dias ocorre gasto excessivo com esta etapa no processo. $\mathrm{E}$, o fato da água vir diretamente da rede de abastecimento de água da cidade, o custo é ainda mais alto para a empresa. Consequentemente, esta atividade acaba gerando impactos que influenciam a sociedade diretamente como, por exemplo, a escassez da água que poderá gerar graves reflexos na saúde, economia e no bem-estar da população.

Em suma, os principais impactos ambientais encontrados no processo produtivo da empresa foram o consumo excessivo de água e a geração de resíduos da construção civil, principalmente aqueles classificados como Classe A pela Resolução CONAMA 307/2005 e como Classe II pela ABNT NBR 10004/2004.

\section{DISCUSSÃO}

Através dos princípios da PML, os pesquisadores desenvolveram sugestões e propostas com o intuito de otimizar o processo produtivo e reduzir os impactos ambientais gerados pela atividade.

\section{- RECICLAGEM DO AÇO:}

Sugere-se que o aço possa ser comercializado com empresas de reciclagem ou utilizado na fabricação de algum produto secundário. Para a primeira proposta, o ideal seria juntar os volumes produzidos na semana em um local próprio e realizar a venda por quilo. Assim sendo, a separação ocorreria ao final da semana de trabalho. Acredita-se que essa ação possibilitaria o aumento de receitas da empresa.

\section{- UTILIZAÇÃO DE RAMPA PARA AUXílIO NO DESPEJO DO CONCRETO NAS FORMAS:}

Sugere-se que, ao invés de dois trabalhadores levantarem a carriola para despejar o cimento, utilize-se rampas próximas às formas, favorecendo no descarregamento do concreto com a carriola. Atualmente, dois colaboradores fazem o serviço de erguê-la e descarregar o concreto na forma. Essa mudança acarretaria na otimização do processo.

\section{- CONSTRUÇÃO DE UM TANQUE PARA REALIZAÇÃO DO PROCESSO DE CURA NAS LAJES:}

Observou-se que a atividade de molhar as lajes para "curar" (endurecer) é realizada diariamente pelo próprio dono da empresa, com o auxílio de uma mangueira que joga água em todas as lajes que estavam estocadas no local. Percebeu-se nessa etapa um desperdício de água, que além de trazer prejuízos econômicos para a empresa, causa impactos ambientais significativos nesse importante recurso natural

Sugere-se a construção de um tanque de concreto retangular, de tamanho um pouco maior que as lajes, sendo que o tanque seria abastecido pela água da rede de abastecimento ou pela própria água da chuva.

\section{- Organização E Limpeza Do Local:}

Sugere-se que todos os materiais que são utilizados no processo produtivo e todos os resíduos gerados pela empresa sejam separados e organizados em locais específicos, removendo-os de 
onde possam vir a causar possíveis acidentes, como por exemplo, vigas, ferramentas ou pedaços de ferro espalhados pelo chão.

\section{- PLANO DE gERENCIAMENTO DE RESíduOS SÓlIDOS, LOCAL DE DESCARTE dO ENTULHO E CERTIFICADOS DE DESTINAÇÃO DE RESÍDUOS:}

Existe na empresa a necessidade da aplicação de um plano que minimize e contribua para o manuseio correto dos resíduos gerados.

Segundo a lei no 12.305/10 referente à Política Nacional dos Resíduos Sólidos (PNRS) é de responsabilidade do gerador dos resíduos os danos causados pelo mau gerenciamento dos mesmos, com isso, a lei determina a necessidade do PGRS.

Ainda em relação aos resíduos, sugere-se que o local onde é feito o descarte de todo o entulho gerado pelo processo de fabricação das lajes seja auditado e acompanhado continuamente. Caso a empresa contratada para realizar este descarte não o faça de forma correta, poderá ocorrer problemas ambientais, além do fato ser caracterizado como crime ambiental, responsabilizando a contratante e a contratada.

\section{CONCLUSÃO}

Tomando como base as propostas apresentadas, verificou-se que existe a ampla necessidade de uma gestão ambiental eficaz e efetiva na empresa estudada. A empresa apresentou um déficit com relação à preocupação ambiental, e tem empregado o pensamento de produção em massa, o que elevará o número de insumos e resíduos produzidos, tendo a necessidade de se adequar em determinados pontos para que assim sejam reduzidos seus impactos. Portanto, a implantação da PML torna-se de extrema necessidade, podendo ser um grande aliado para a minimização dos resíduos e impactos ambientais gerados, melhorando a imagem da empresa e sua lucratividade.

Com o fluxograma de processos foi possível relacionar os principais impactos ligados à atividade, que se relacionaram principalmente ao consumo de água, consumo de recursos naturais e gerenciamento inadequado dos resíduos sólidos gerados no processo, sendo sugeridas melhorias em diversas áreas e processos da empresa.

Dentre as soluções, observou-se a necessidade de melhor compreensão da empresa frente aos aspectos referentes à PML, o gerenciamento de resíduos e os impactos ambientais gerados pelo processo produtivo. Caso essas ferramentas sejam aplicadas e aprimoradas frequentemente, espera-se que se tornem parte da estratégia competitiva da empresa.

\section{REFERÊNCIAS}

ASSOCIAÇÃO BRASILEIRA DE NORMAS TÉCNICAS. Resíduos sólidos - Classificação: NBR 10004. Rio de Janeiro, 2004.

BRASIL. Conselho Nacional do Meio Ambiente. Resolução n. 307 de 5 de julho de 2002. Disponível em: <http://www.mma.gov.br/port/conama/legislacao/CONAMA RES CONS 2002 307.pdf> Acesso em: 04 agosto 2017.

BRASIL, Decreto no 7.404 de 23 de dezembro de 2010. Regulamenta a Lei n. 0 12.305, de 02 de agosto de 2010. Institui a Política Nacional de Resíduos Sólidos, altera a Lei 9605, de 12 de fevereiro de 1998, e dá outras providências. Disponível em: < http://www.planalto.gov.br/ccivil 03/ ato2007-2010/2010/lei/I12305.htm >. Acesso em: 22 setembro 2017. 
BRASIL. Lei № 12.305 de 02 agosto de 2010. Política Nacional de Resíduos Sólidos altera a Lei no 9.605, de 12 de fevereiro de 1998 e dá outras providências. Disponível em: < http://www.mma.gov.br/port/conama/legiabre.cfm?codlegi=636 >. Acesso em: 22 setembro 2017.

ECYCLE Digital. Processo de produção do cimento gera emissões e pode diminuir biodiversidade. Disponível em: http://www.ecycle.com.br/component/content/article/35/1569-processo-deproducao-do-cimento-gera-emissoes-e-pode-diminuir-biodiversidade.html. Acesso em: 4 agosto 2017.

UNITED NATIONS ENVIRONMENTAL PROGRAMME (UNEP). Disponível em: <http://www.uneptie.org/pc/cp> Acesso em: 4 agosto 2017. 